\title{
THE ADSORPTION AND INCORPORATION OF OXYGEN ON Cu(100) AND ITS REACTION WITH CARBON MONOXIDE; COMPARISON WITH $\mathrm{Cu}(111)$ AND $\mathrm{Cu}(110)$
}

\author{
F.H.P.M. HABRAKEN, C.M.A.M. MESTERS and G.A. BOOTSMA * \\ Van 't Hoff Laboratory, University of Utrecht, Padualaan 8, $3584 \mathrm{CH}$ Utrecht, The Netherlands
}

Received 6 February 1980; accepted for publication 24 March 1980

Ellipsometry, LEED, Auger electron spectroscopy and monitoring of work function changes have been used to study the interactions of $\mathrm{O}_{2}$ and $\mathrm{N}_{2} \mathrm{O}$ with a clean annealed $\mathrm{Cu}(100)$ surface and of the reaction of $\mathrm{CO}$ with sorbed oxygen. Gas pressures were in the range $10^{-7}-10^{-4}$ Torr and crystal temperatures varied between $25-400^{\circ} \mathrm{C}$. The initial interaction of oxygen with $\mathrm{Cu}(100)$ occurs in three stages. Oxygen chemisorbs with an initial sticking coefficient of $\sim 10^{-2}$ at room temperature and an apparent activation energy of $1.3-3.5 \mathrm{kcal} / \mathrm{mol}$, depending on the substrate temperature. The first stage is the formation of a $(\sqrt{2} \times \sqrt{2})$ R $45^{\circ}$ LEED pattern up to a coverage of 0.5 , which is converted with an apparent activation energy of $3.2 \mathrm{kcal} / \mathrm{mol}$ to a $(\sqrt{2} \times 2 \sqrt{2}) \mathrm{R} 45^{\circ}$ structure at a coverage of 0.75 in the second stage. The work function increases inthe first stage in an amount of $\sim 300 \mathrm{meV}$, but decreases in the second stage to the value of the clean surface. In a third stage after an induction period further oxygen uptake could be registered only with ellipsometry. The apparent activation energy is $4.5 \mathrm{kcal} / \mathrm{mol}$. The initial decomposition probability of $\mathrm{N}_{2} \mathrm{O}$ at room temperature is $5 \times 10^{-5}$, its apparent activation energy $3.2 \mathrm{kcal} / \mathrm{mol}$. The LEED patterns observed were the same as with $\mathrm{O}_{2}$. The sorbed oxygen can be removed at all coverages with $\mathrm{CO}$. The reaction appears to follow LangmuirHinshelwood kinetics with an activation energy for the reaction $\mathrm{CO}_{\mathrm{ad}}+\mathrm{O}_{\mathrm{ad}} \rightarrow \mathrm{CO}_{2}$ of $19-$ $20 \mathrm{kcal} / \mathrm{mol}$. A comparison is made with the data obtained for $\mathrm{Cu}(111)$ and $\mathrm{Cu}(110)$.

\section{Introduction}

The interaction of $\mathrm{O}_{2}$ with $\mathrm{Cu}(100)$ has been extensively studied with modern surface analytical techniques $[1-21]$. However, kinetic data are scarce and contradictory.

LEED studies have shown that low exposures $\left(\sim 100 \mathrm{~L} ; 1 \mathrm{~L}=10^{-6}\right.$ Torr $s=$ $1.33 \times 10^{-4} \mathrm{~Pa} \mathrm{~s}$ ) result in a weak "4-spot" pattern $[1,3,6-8]$ which is converted into an oblique structure $[1,2]$ or into a $(\sqrt{2} \times \sqrt{ } 2) \mathrm{R} 45^{\circ}$ pattern $[3-8]$ when the exposures are increased to about $10^{3} \mathrm{~L}$. In early LEED intensity studies $[9,10]$ it has been tentatively suggested that the $(\sqrt{ } 2 \times \sqrt{ } 2) \mathrm{R} 45^{\circ}$ pattern arises from a reconstructed copper-oxygen layer. More recent angular resolved AES [11], XPS

* Present address: Department of Applied Physics, Twente University of Technology, P.O. Box 217,7500 AE Enschede, The Netherlands. 
$[12,13]$ and SIMS [14] measurements suggest that the oxygen atoms are located in sites with four-fold symmetry. In ref. [13] it has been proposed that the oxygen atom resides in the plane of the surface whereas in ref. [14] the adsorbed atom is supposed to be located $1.2-1.5 \AA$ above the surface plane.

At exposures larger than $10^{3} \mathrm{~L}$ a $(\sqrt{ } 2 \times 2 \sqrt{ } 2) \mathrm{R} 45^{\circ}$ pattern appears $[1-4,6-8]$. According to XPS [6], AFS [8] and UPS [15] data, reconstruction or incorporation accompanies the formation of this pattern. This is in keeping with the work function measurements of Hofmann et al. [7] and Benndorf et al. [8] who observed that the work function reaches a maximum of about $330 \mathrm{meV}$ when the $(\sqrt{ } 2 \times \sqrt{2}) \mathrm{R} 45^{\circ}$ pattern is developed. The formation of the subsequent pattern caused a decrease in work function to about the value of the clean surface. This decrease has not been observed by Boggio [16] and Delchar [17].

In a very recent study of LEED spot patterns and intensities it was concluded that at $\sim 200^{\circ} \mathrm{C}$ oxygen is initially adsorbed onto a 2 -fold bridge site and subsequently may be drawn into 4-fold sites, coplanar with the top metal atom layer [18]. The $(\sqrt{2} \times 2 \sqrt{2}) \mathrm{R} 45^{\circ}$ pattern was ascribed to a mixed layer involving 2-and 4 -fold sites (oxygen coverage $\sim \frac{3}{4}$ monolayer). However, the authors consider their conclusion not as definitive because of the poor agreement between theory and experiment [18].

At room temperature, the initial sticking probability appeared to be 0.03 [7], and in the temperature range $20-450^{\circ} \mathrm{C}$ for the increase and decrease of the work function an apparent activation energy of 3-4 kcal $/ \mathrm{mol}$ [7] and of $1-2 \mathrm{kcal} / \mathrm{mol}$ [8] has been reported. In an ellipsometric study at $\lambda=5461 \AA$, Hofmann [19] measured a decrease in $\Delta$ of $0.7^{\circ}$ as a result of an exposure of $4500 \mathrm{~L} \mathrm{O}_{2}$ on $\mathrm{Cu}(100)$ at room temperature; $\psi$ decreased up to $50 \mathrm{~L}$ with $\sim 0.05^{\circ}$, whereafter an increase of $0.2^{\circ}$ up to $300 \mathrm{~L}$ was observed. Upon further oxygen exposure $\psi$ remained constant.

According to angle-resolved UPS, oxide formation starts at room temperature at exposures above $10^{6} \mathrm{~L}$ [20]. It has been proposed that this surface oxide has the composition of a $\mathrm{Cu}_{2} \mathrm{O}$ compound [21]. Shake-up satellites in XPS, characteristic for $\mathrm{CuO}$ have been observed only after oxygen exposures of $10^{9} \mathrm{~L}$ at $300^{\circ} \mathrm{C}$ [6]. An earlier ellipsometric study of the oxidation of $\mathrm{Cu}(100)$ at atmospheric pressures and at temperatures of $70-178^{\circ} \mathrm{C}$ [22] revealed that the $(100)$ plane has a larger oxidation rate than the other low-index copper surfaces and that under these conditions thick oxide layers $(\sim 1000 \AA)$ are readily formed.

On copper surfaces nitrous oxide decomposes into desorbing $\mathrm{N}_{2}$ and a chemisorbed oxygen atom $[2,23]$. Two complicated LEED superstructures have been observed by Ertl [2] upon exposure of $10^{3} \mathrm{~L} \mathrm{~N}_{2} \mathrm{O}$ to $\mathrm{Cu}(100)$ at $500^{\circ} \mathrm{C}$.

At room temperature $\mathrm{CO}$ is only weakly adsorbed on $\mathrm{Cu}(100)$ [24]. The reaction of $\mathrm{CO}$ with oxygen adsorbed on $\mathrm{Cu}(100)$ has been investigated with LEED [25]. The intensity of a spot of the $(\sqrt{ } 2 \times 2 \sqrt{ } 2) R 45^{\circ}$ pattern was measured as a function of $\mathrm{CO}$ exposure, and an activation energy for this reaction of about $30 \mathrm{kcal} / \mathrm{mol}$ has been obtained [25]. 
In previous papers [26-28] results of the study of the kinetics of the interactions of $\mathrm{O}_{2}$ and $\mathrm{N}_{2} \mathrm{O}$ with $\mathrm{Cu}(111)$ and $\mathrm{Cu}(110)$ surfaces and of the reaction of $\mathrm{CO}$ with sorbed oxygen have been presented. In this paper we describe the same reactions on a clean annealed $\mathrm{Cu}(100)$ surface. The measuring techniques used were ellipsometry, AES, LEED and monitoring of work function changes. In the last section the results obtained for the three low-index copper plancs are compared.

\section{Experimental}

The experimental arrangement and procedures were the same as in refs. [26] and [27]. The work function measurements were performed with a self-compensating Kelvin probe, which was purchased from the Kernforschungsanlage Jülich $\mathrm{GmbH}$. The probe has been described in ref. [29].

\section{The interaction of $\mathrm{O}_{2}$ with $\mathrm{Cu}(100)$}

Exposures of $\mathrm{O}_{2}$ to a clean annealed $\mathrm{Cu}(100)$ surface were carried out at pressures between $1 \times 10^{-7}$ and $8 \times 10^{-4}$ Torr and at crystal temperatures ranging from 25 to $400^{\circ} \mathrm{C}$. Fig. 1 shows the response of the four techniques to oxygen exposure

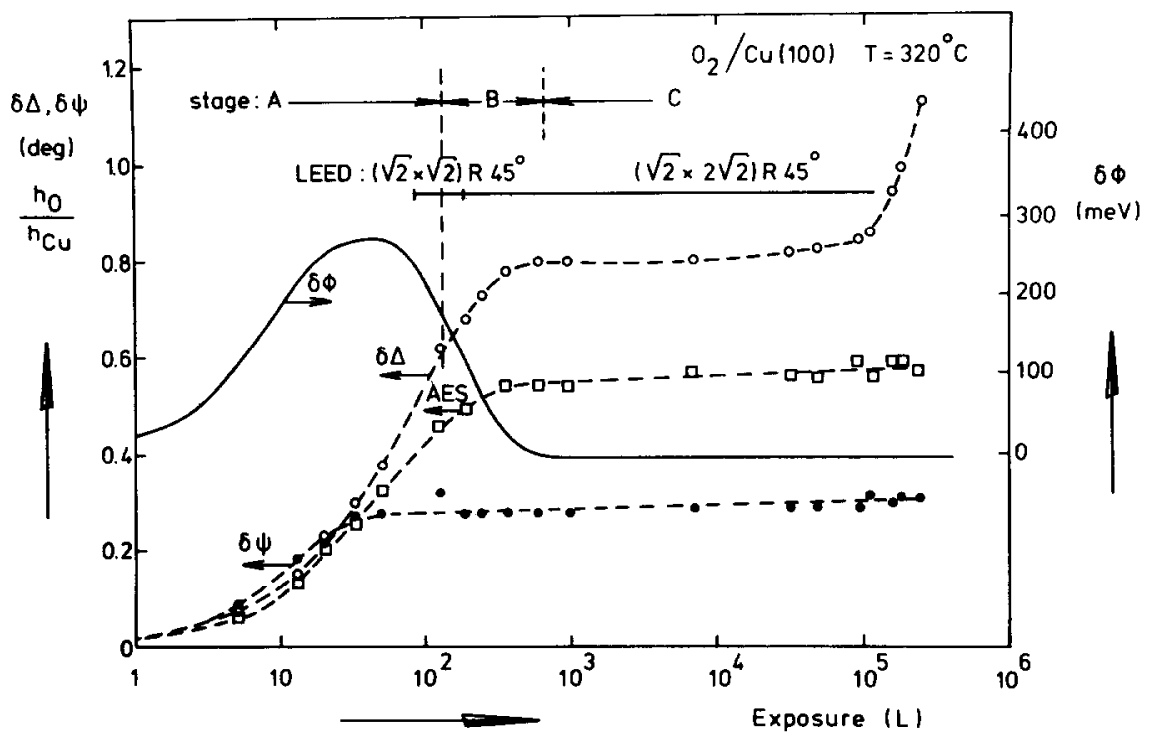

Fig. 1. Oxygen Auger signal (AES), $\delta \Delta, \delta \psi, \delta \phi$ and LEED patterns versus oxygen exposure at $320^{\circ} \mathrm{C}$ to a clean annealed $\mathrm{Cu}(100)$ surface ( $\delta \Delta$ and $\delta \psi$ obtained by two-zone measurements). 
at $320^{\circ} \mathrm{C}$. By analogy with ref. [28], a distinction can be made between different stages; these will be discussed in more detail below.

\subsection{The low exposure region (stages $A$ and $B$ )}

\subsubsection{Determination of the oxygen coverage}

A linear relationship between the oxygen Auger signal and $\delta \Delta$ was found upon the initial interaction of $\mathrm{O}_{2}$ with $\mathrm{Cu}(100)$ up to $\delta \Delta \approx 0.65^{\circ}$ (fig. 2). No dependence on the crystal temperature $T\left(T<400^{\circ} \mathrm{C}\right)$ was observed, contrary to the results on $\mathrm{Cu}(110)$ [27]. The plane of incidence made an angle of about $45^{\circ}$ with the [011] direction. In the coverage region considered here, the copper $920 \mathrm{eV}$ peak is not measurably attenuated; thus it is concluded that up to $0.65^{\circ}, \delta \Delta$ is proportional to the coverage.

A calibration of the coverage is obtained from LEED data. At a $\delta \Delta$ of about $0.65^{\circ}$ the $(\sqrt{2} \times \sqrt{ } 2) R 45^{\circ}$ pattern is developed. If this superstructure is assumed to correspond to $\theta \approx 0.5$ (oxygen atoms per copper surface atom) [7,11-14], it follows that

$\theta=(0.77 \pm 0.08) \delta \Delta$

for $\delta \Delta \leqslant 0.65^{\circ}$. A comparison of the oxygen Auger signals for $\mathrm{Cu}(100)$ (fig. 2) with those for the other copper planes $[26,27]$ yields also within $10 \%$ the same calibration as given by eq. (1).

The other ellipsometric parameter, $\delta \psi$, increases up to $\delta \psi=0.3^{\circ}$ at $\delta \Delta=0.4^{\circ}$

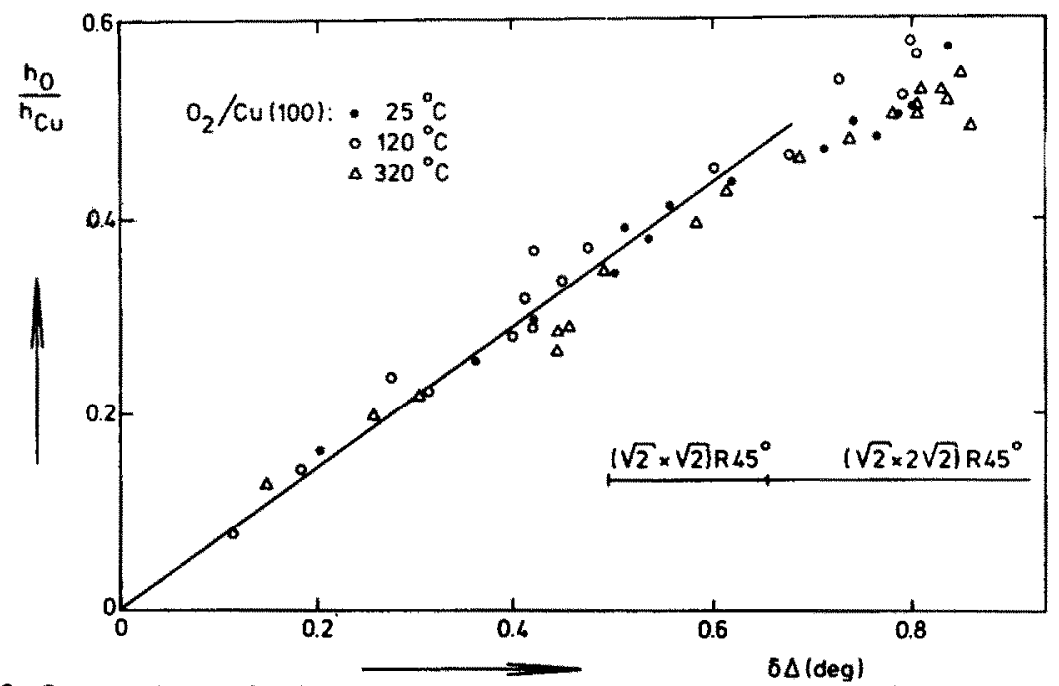

Fig. 2. Oxygen Auger signal and LEED patterns versus $\delta \Delta$ upon adsorption of oxygen on $\mathrm{Cu}(100)$ at different temperatures. 
and remains constant upon further oxygen exposure. The ellipsometric data and their plane-specificity will be discussed in more detail in a forthcoming paper [30].

\subsubsection{Adsorption of oxygen}

Examples of oxygen adsorption curves resulting from off-null irradiance measurements [26] are presented in fig. 3 . The oxygen pressures were in the $10^{-7}$ $10^{-5}$ Torr range. In the considered temperature range $\left(25-400^{\circ} \mathrm{C}\right)$ and exposure region $(\leqslant 1200 \mathrm{~L})$ the maximum $\delta \Delta$ attained is $0.8^{\circ}$. The rate of change of $\delta \Delta$ appeared to be proportional to the pressure and increased with increasing temperature. No effect of the ionization gauge could be detected.

With LEED an increase in background intensity was observed initially. The $(\sqrt{ } 2 \times \sqrt{ } 2) \mathrm{R} 45^{\circ}$ pattern was visible after $\delta \Delta \approx 0.5^{\circ}$. We did not observe the "4-spot" pattern observed by other authors $[1,3,6-8]$. When $\delta \Delta$ was about equal to $0.7^{\circ}$ extra spots due to a $(\sqrt{ } 2 \times 2 \sqrt{ } 2) \mathrm{R} 45^{\circ}$ pattern became visible. The latter pattern was at its most distinct at $\delta \Delta=0.8^{\circ}$.

Because changes in work function upon exposure of oxygen to $\mathrm{Cu}(100)$ have recently been reported in detail by other authors [7,8], they will be discussed here only briefly. As shown in figs. 1 and $3, \delta \phi$ increases upon the initial interaction with $\mathrm{O}_{2}$ and reaches a maximum $(250-350 \mathrm{meV}$, dependent on $T$ ) when $\delta \Delta=$ $0.4-0.5^{\circ}$. Thereafter $\delta \phi$ decreases, to about zero when $T \leqslant 350^{\circ} \mathrm{C}$, and to values slightly larger when $T \geqslant 350^{\circ} \mathrm{C}$. This behaviour is in accordance with refs. [7] and

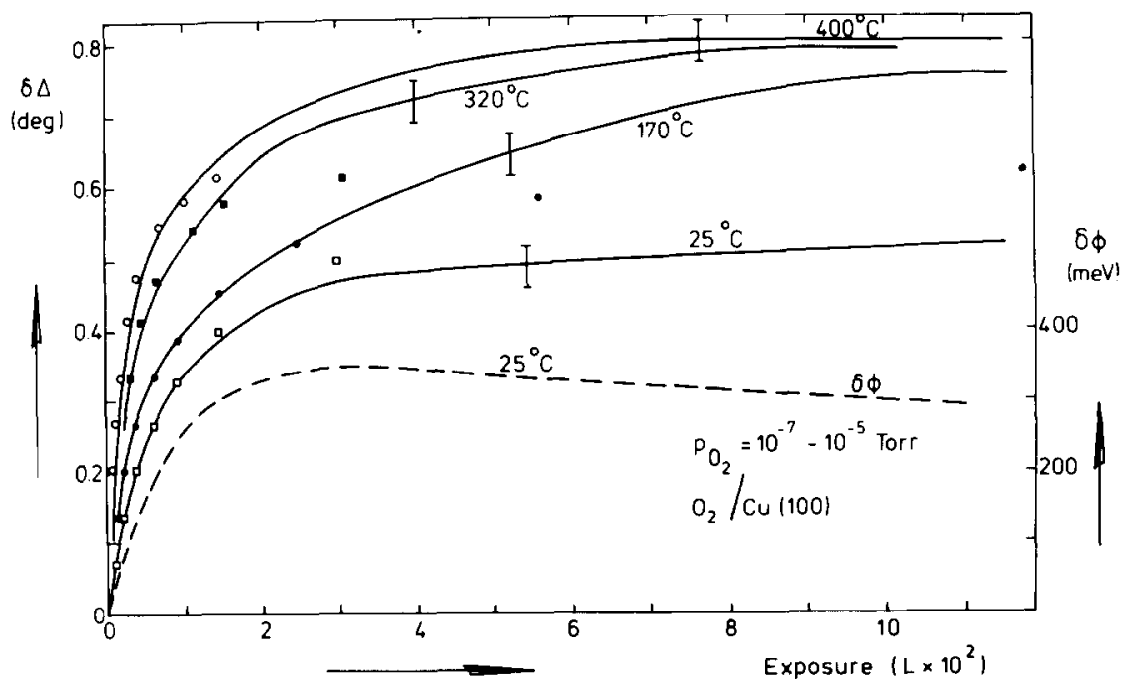

Fig. 3. $\delta \Delta$ versus exposure of $\mathrm{O}_{2}$ to a clean annealed $\mathrm{Cu}(100)$ surface (solid lines, experimental errors indicated). The symbols denote the integral of eq. (2) with: (ㅁ) $s(0)=9.2 \times 10^{-3},(\bullet)$ $s(0)=1.9 \times 10^{-2}$, (口) $s(0)=4.4 \times 10^{-2}$, (0) $s(0)=6.1 \times 10^{-2} ; \delta \phi$ versus exposure at room temperature. 
[8], except that the maximum does not coincide with $\theta \approx 0.5\left(\delta \Delta=0.65^{\circ}\right)$, although it was suggested in ref. [7] that it did.

\subsection{The high exposure region (stage C)}

After $\delta \Delta$ had reached saturation, no changes in $\delta \Delta, \delta \psi, \delta \phi$, oxygen Auger signal or in the LEED pattern could be observed during exposures up to $5 \times 10^{4} \mathrm{~L}$ (figs. 1 and 4). A further linear increase of $\delta \Delta$ occurred after this induction period, together with an increase of the background intensity of the $(\sqrt{ } 2 \times 2 \sqrt{2}) \mathrm{R} 45^{\circ}$ pattern. The rate of change of $\Delta$ increased with increasing temperature and appeared to be proportional to the oxygen pressure in the pressure region considered $(5 \mathrm{X}$ $10^{-5}-8 \times 10^{-4}$ Torr).

During the above-mentioned induction period oxygen had to be in the gas phase: the length of the period was inversely proportional to the oxygen pressure and rather independent of the temperature. This behaviour holds for sputter-cleaned and annealed surfaces. When a surface, exposed to oxygen up to $\sim 10^{4} \mathrm{~L}$ or more, was cleaned by reduction with $\mathrm{CO}$, the next induction period was about $50 \%$ shorter. The induction period even totally disappeared after a second oxidationreduction cycle.

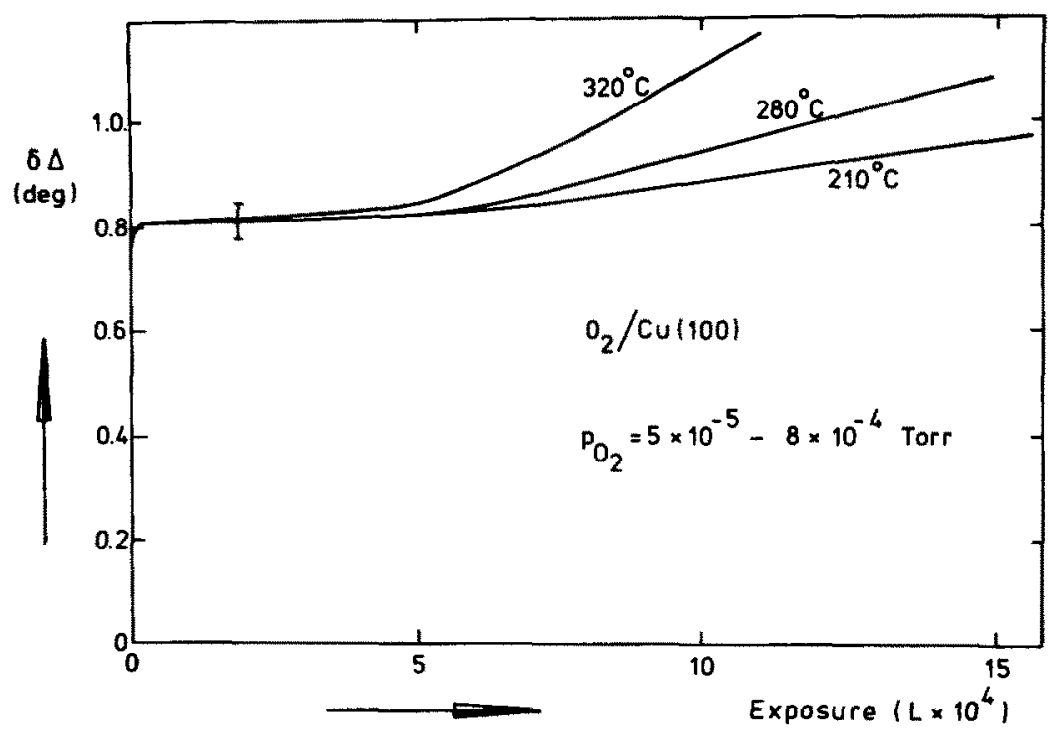

Fig. 4. $\delta \Delta$ versus exposure of oxygen to a clean annealed $\mathrm{Cu}(100)$ surface (off null irradiance measurements). Experimental errors indicated. 


\subsection{Discussion}

The initial interaction of $\mathrm{O}_{2}$ with $\mathrm{Cu}(100)$ can be divided phenomenologically into the three stages A, B and C (fig. 1), as described above.

As in refs. [7] and [8], we regard stage A (formation of the $(\sqrt{2} \times \sqrt{2}) \mathrm{R} 45^{\circ}$ pattern) as a chemisorption process; arguments for this are that $\phi$ initially increases and that apparently the $(\sqrt{2} \times \sqrt{2}) \mathrm{R} 45^{\circ}$ LEED pattern does not originate from a reconstructed surface. The initial sticking coefficient $s(0)$ of $\mathrm{O}_{2}$ on $\mathrm{Cu}(100)$ at $25^{\circ} \mathrm{C}$, obtained with the calibration described in section 3.1.1 appears to be $9 \times$ $10^{-3}$. In view of the experimental errors in exposure scales, this value agrees reasonably well with $s(0)=0.03$ of ref. [7].

As shown in fig. 3 the adsorption curves up to $\delta \Delta=0.55^{\circ}$ can be described with simple second order kinetics. The symbols in this figure represent the integral of

$s\left(\theta^{\prime}\right)=s(0)\left(1-\theta^{\prime}\right)^{2}$.

It has been assumed that $\delta \Delta=0.65^{\circ}$ represents the saturation coverage of the chemisorption stage with $\theta=0.5$, and that the surface consists of specific sites of two nearest-neighbour (nn) copper atoms; thus $\theta^{\prime}=2 \theta$. As discussed in ref. [27] eq. (2) can be obtained in two ways. Firstly one can assume Langmuir kinetics, according to which physisorbed oxygen molecules are supposed to have a negligible effect on the chemisorption kinetics and a gas molecule has a probability $s(0)$ for chemisorption, only when it impinges on an empty nn site pair. In order to obtain eq. (2) the chemisorbed atoms should be distributed randomly over the sites; thus the $\mathrm{nn}$ interaction energy $\omega[31]$ should be about zero. Secondly one can assume precursor-state kinetics. Then $\omega=0$ also and the precursor-state parameter $K$, defined in refs. $[27,31]$, must be equal to one to give eq. (2).

The Arrhenius plot of $s(0)$ (fig. 5) shows that the apparent activation energy, $E_{\text {act }}$, increases with increasing crystal temperature. Phenomenologically two regions can be distinguished: $T<200^{\circ} \mathrm{C}$ with $E_{\text {act }}=1.3 \mathrm{kcal} / \mathrm{mol}$ and $200<T<400^{\circ} \mathrm{C}$ with $E_{\text {act }}=3.5 \mathrm{kcal} / \mathrm{mol}$. A similar temperature dependence has been found for the chemisorption of $\mathrm{O}_{2}$ on $\mathrm{Cu}(111)$ [26]. There $E_{\text {act }}$ was $1.7 \mathrm{kcal} / \mathrm{mol}$ for $T<230^{\circ} \mathrm{C}$ and $4 \mathrm{kcal} / \mathrm{mol}$ for $230<T<400^{\circ} \mathrm{C}$. On the $\mathrm{Cu}(111)$ plane the sticking coefficient appeared to be initially independent of the coverage, which has been explained with a precursor-state model. Because of the similarity in temperature dependence observed for both planes, the adsorption mechanism may also be the same and the precursor-state model may also hold for $\mathrm{Cu}(100)$. In this model the activation energy is interpreted as the difference between the energy barriers for chemisorption and desorption of fully accommodated precursor molecules provided the probability $\alpha$ of trapping in the precursor state is independent of $T$. The change in apparent $E_{\text {act }}$ may be due to a change in $\alpha$. The adsorption curves give no indication for the occurrence of two different processes in the two temperature regions.

The deviations from the second order kinetics at $\delta \Delta>0.55^{\circ}$ (fig. 3) are probably due to an overlap between the formation of the phases corresponding to the 


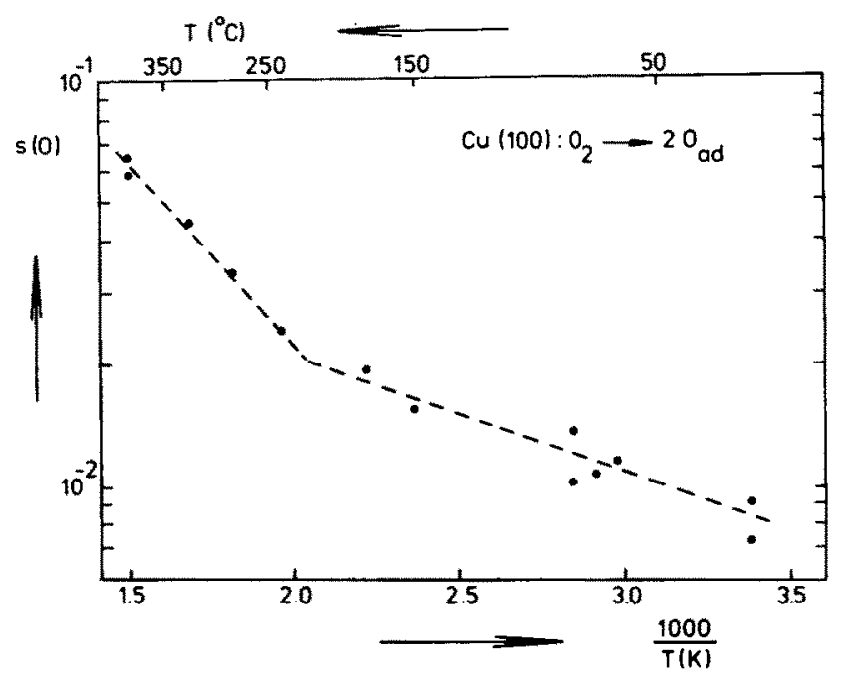

Fig. 5. Arrhenius plot of $s(0)$ for adsorption of $\mathrm{O}_{2}$ on $\mathrm{Cu}(100)$.

$(\sqrt{ } 2 \times \sqrt{2}) \mathrm{R} 45^{\circ}$ LEED pattern and the $(\sqrt{ } 2 \times 2 \sqrt{2}) \mathrm{R} 45^{\circ}$ pattern; the existence of this overlap has already been mentioned by Lee and Farnsworth [1]. The overlap may also explain the position of the maximum in the $\delta \phi$ curves. The $\delta \Delta$ versus exposure curves show no discontinuities. Fig. 6 shows an Arrhenius plot of the rate of change of $\delta \Delta$ at $\delta \Delta=0.7^{\circ}\left(k_{\mathrm{B}}\right)$. From the slope an apparent activation energy of $3.2 \pm 0.4 \mathrm{kcal} / \mathrm{mol}$ is obtained, in agreement with ref. [7]. The difference between $E_{\text {act }}$ for $0<\delta \Delta<0.55^{\circ}(1.3 \mathrm{kcal} / \mathrm{mol})$ and $E_{\text {act }}$ at $\delta \Delta=0.7^{\circ}$ for $25<T<200^{\circ} \mathrm{C}$ indicates that in this temperature region a different process is rate limiting at the different coverages.

Benndorf et al. [8] have reported that the value of the maximum of the change of the work function upon interaction of $\mathrm{O}_{2}$ with $\mathrm{Cu}(100)$ decreases with increasing $T$ for $T<200^{\circ} \mathrm{C}$ and increases slightly for $200<T<500^{\circ} \mathrm{C}$. This can now be explained. Since for $25<T<200^{\circ} \mathrm{C}$ the apparent activation energy for stage A with increasing $\delta \phi(1.3 \mathrm{kcal} / \mathrm{mol})$ is lower than for stage B with decreasing $\delta \phi(3.2 \mathrm{kcal} / \mathrm{mol})$, the $\delta \phi$ maximum is attained at decreasing coverages for increasing temperature. For $T>200^{\circ} \mathrm{C}$ the activation energy in stage A $(3.5 \mathrm{kcal} /$ $\mathrm{mol})$ is slightly larger than in stage $\mathrm{B}(3.2 \mathrm{kcal} / \mathrm{mol})$, thus the $\delta \phi$ maximum will show a small shift to higher coverages and the value of the maximum will slightly increase.

In agreement with other authors $[7,8,18]$ we regard stage $B$ as being incorporation of oxygen in the topmost copper layer, which gives rise to a $(\sqrt{2} \times 2 \sqrt{2}) \mathrm{R} 45^{\circ}$ LEED pattern, a decrease of $\delta \phi$ and a slight deviation from the proportionality between the oxygen Auger signal and $\delta \Delta$ for $\delta \Delta>0.6^{\circ}$ (fig. 2). Both for $\mathrm{Cu}(111$ ) [26] and for $\mathrm{Cu}(110)$ [28] we have strong arguments that a ratio of 2.3 holds for 


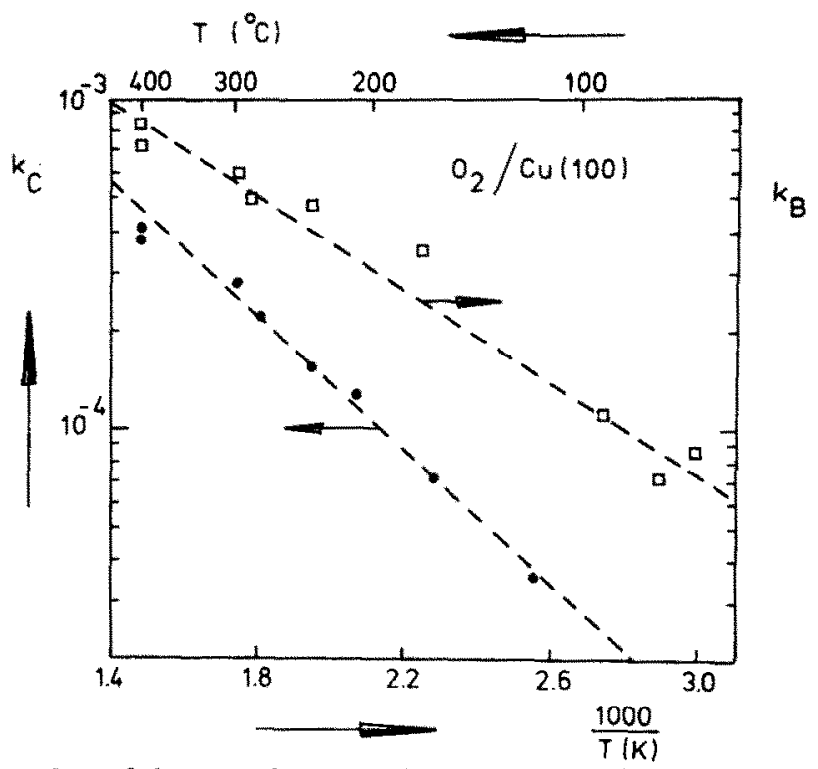

Fig. 6. Arrhenius plots of the rate of change of $\delta \Delta$ at $\delta \Delta=0.7\left(k_{\mathrm{B}}\right)$ and in stage $\mathrm{C}\left(k_{\mathrm{C}}\right)$ (arbitrary units).

the $\delta \Delta$ per $O$ atom in stage $A$ to the $\delta \Delta$ per $O$ atom in stage $B$. If this ratio is assumed to hold for the $\mathrm{Cu}(100)$ system as well, then the oxygen coverage at $\delta \Delta=$ $0.8^{\circ}\left((\sqrt{2} \times 2 \sqrt{2}) \mathrm{R} 45^{\circ}\right.$ LEED pattern $)$ is $\frac{3}{4}$ of a monolayer, which is in excellent agreement with ref. [18]. With this calibration a sticking coefficient at $\theta \approx 0.5$ of $1.5 \times 10^{-3}$ around $200^{\circ} \mathrm{C}$ is calculated. This value is one order of magnitude larger than for $\mathrm{Cu}(110)$ and three orders larger than for $\mathrm{Cu}(111)$. If, as suggested by other authors [7], the coverage at the $(\sqrt{2} \times 2 \sqrt{2}) \mathrm{R} 45^{\circ}$ pattern is one monolayer, the value for $s(0.5)$ becomes twice as large.

Stage $C$ is characterized by an induction exposure $\left(\sim 5 \times 10^{4} \mathrm{~L}\right)$ and thereafter an increase in $\delta \Delta$. The length of the induction period is determined by the oxygen pressure, but no oxygen uptake could be registered with any of our techniques. We suggest that during this period a number of nuclei of some kind are formed, which still remain after reduction with $\mathrm{CO}$ in our conditions. The rate of change of $\delta \Delta$ after this induction period has been depicted in an Arrhenius plot ( $k_{\mathrm{C}}$, fig. 6). From this plot an apparent activation energy of $4.5 \pm 0.3 \mathrm{kcal} / \mathrm{mol}$ is obtained, which is equal to the apparent activation energy for the similar stage on $\mathrm{Cu}(110)$ [28], where no induction effect has been observed. Further comparison shows that the rate of change of $\delta \Delta$ is also roughly equal for both planes, indicating that a non plane-specific process is rate limiting. The proportionality of the rates to the oxygen pressure suggests that the rate limiting process takes place at the surface. This process could be the dissociation of a physisorbed molecular precursor state. 
In the present work no measurements were performed in the exposure range of $10^{6} \mathrm{~L}$, where a further change of $\phi$ and the Auger signal [8] has been observed and $\mathrm{Cu}_{2} \mathrm{O}$ formation has been reported to start [21]. Jardinier-Offergeld and Bouillon [32] have studied the kinetics of the formation and growth of oxide nuclei on a $\mathrm{Cu}(100)$ surface at oxygen pressures in the range $10^{-4}-10^{-3}$ Torr and at temperatures of $511-735^{\circ} \mathrm{C}$ with a microgravimetric technique. If their results are extrapolated into our temperature range, it would appear, as with $\mathrm{Cu}(110)$ [28], that in the present study the critical oxygen exposure at which the formation and growth of nuclei starts was not reached.

\section{Decomposition of $\mathrm{N}_{2} \mathrm{O}$}

Exposures of $\mathrm{N}_{2} \mathrm{O}$ to a clean annealed $\mathrm{Cu}(100)$ surface were carried out at pressures between $1 \times 10^{-5}$ and $8 \times 10^{-4}$ Torr and at crystal temperatures ranging from 25 to $400^{\circ} \mathrm{C}$. During the exposures the ion gauge was switched off to prevent the formation of NO species [26].

In fig. $7 \delta \Delta$ is depicted as a function of $\mathrm{N}_{2} \mathrm{O}$ exposure at different temperatures. Auger spectra did not show any peak that could be attributed to nitrogen. Fig. 7 shows that the initial reaction probability (number of oxygen atoms deposited per incident $\mathrm{N}_{2} \mathrm{O}$ molecule) increases with increasing temperature and that in our exposure region $\left(<10^{6} \mathrm{~L}\right) \delta \Delta$ saturates at $0.8^{\circ}$ for $T \geqslant 270^{\circ} \mathrm{C}$. As with $\mathrm{O}_{2}$ a $(\sqrt{ } 2 \times$

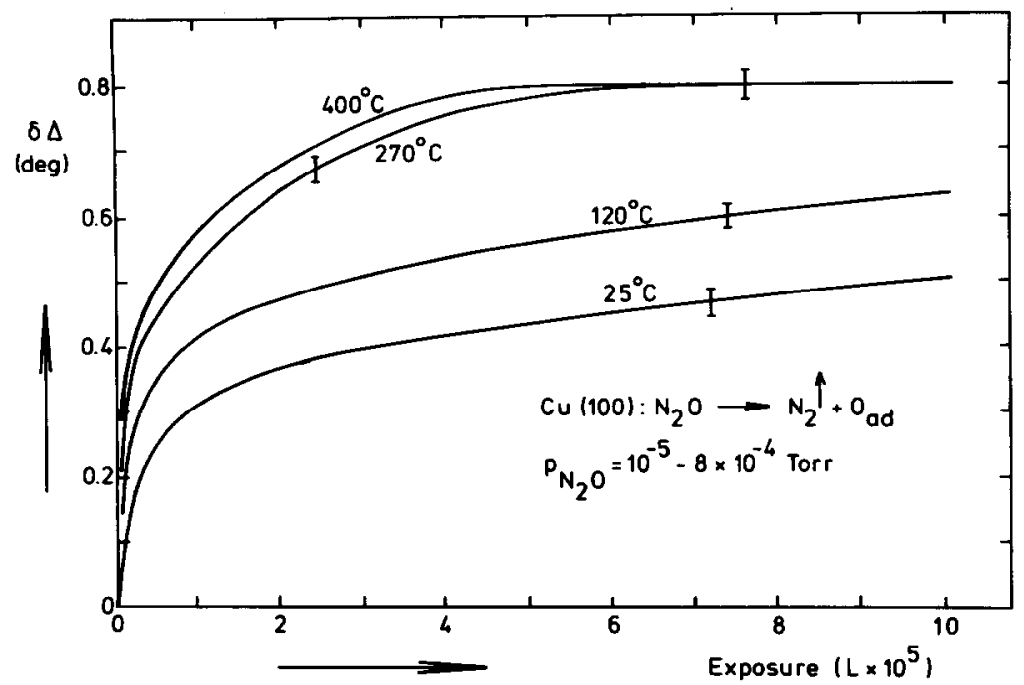

Fig. 7. $\delta \Delta$ versus exposure of $\mathrm{N}_{2} \mathrm{O}$ to a clean annealed $\mathrm{Cu}(100)$ surface. Off-null irradiance measurements. 
Table 1

Decomposition probability of $\mathrm{N}_{2} \mathrm{O}$ at zero coverage as a function of crystal temperature

\begin{tabular}{llllllll}
\hline$T\left({ }^{\circ} \mathrm{C}\right)$ & 25 & 120 & 170 & 215 & 270 & 320 & 370 \\
\hline$s(0) \times 10^{4}$ & 0.5 & 2 & 2.5 & 4 & 6.5 & 6 & 8 \\
\hline
\end{tabular}

$\sqrt{ } 2) \mathrm{R} 45^{\circ}$ LEED pattern was observed around $\delta \Delta \approx 0.6^{\circ}$ and a $(\sqrt{ } 2 \times 2 \sqrt{ } 2) \mathrm{R} 45^{\circ}$ pattern at $\delta \Delta=0.8^{\circ}$.

At room temperature the initial reaction probability $s(0)$ is $5 \times 10^{-5}$. Values of $s(0)$ at different temperatures are given in table 1 . For $s(0)$ an apparent activation energy of $3.2 \mathrm{kcal} / \mathrm{mol}$ is found; the pre-exponential factor appears to be about $10^{-2}$.

The reaction probability decreases exponentially with $\theta$, and Arrhenius plots at different $\delta \Delta$ reveal that the apparent activation energy increases with $\theta$ (e.g. $E_{\text {act }}=$ $6.4 \mathrm{kcal} / \mathrm{mol}$ at $\delta \Delta=0.5^{\circ}$ ). A strong decrease of $s$ with $\theta$ and an increasing activation energy have also been observed for $\mathrm{N}_{2} \mathrm{O}$ on $\mathrm{Cu}(110)$ [27]. Both for $\mathrm{Cu}(111)$ and for $\mathrm{Cu}(110)$ a precursor-state model has been proposed to explain the kinetics of the $\mathrm{N}_{2} \mathrm{O}$ decomposition $[26,27]$. So we suggest that the precursor model is also appropriate for $\mathrm{Cu}(100)$. A more detailed discussion of the kinetics of the $\mathrm{N}_{2} \mathrm{O}$ decomposition on the three low-index copper planes will be given in a forthcoming paper [33].

The decomposition of $\mathrm{N}_{2} \mathrm{O}$ on a surface covered with about half a monolayer oxygen atoms occurs more easily on $\mathrm{Cu}(100)$ than on the other low-index copper planes (fig. 7). If it is assumed that the $(\sqrt{ } 2 \times 2 \sqrt{ } 2) \mathrm{R} 45^{\circ}$ LEED pattern corresponds to $\frac{3}{4}$ monolayer of oxygen atoms, then a decomposition probability of $5 \times 10^{-6}$ at $\delta \Delta=0.7^{\circ}$ and $270^{\circ} \mathrm{C}$, for instance, can be calculated. This behaviour is comparable with the interaction of $\mathrm{O}_{2}$ with $\mathrm{Cu}(100)$, where the incorporation of oxygen also occurs much more easily than on $\mathrm{Cu}(110)$ and $\mathrm{Cu}(111)$.

\section{The oxidation of $\mathrm{CO}$ by preadsorbed oxygen}

\subsection{Initial oxygen coverage $<0.5$ monolayer}

Surfaces with various oxygen coverages were exposed to $\mathrm{CO}$ at pressures of $2 \times$ $10^{-4}-8 \times 10^{-4}$ Torr and at crystal temperatures of $200-400^{\circ} \mathrm{C}$. During the exposures the ionisation gauge was switched off to prevent the formation of reactive $\mathrm{CO}$ species $[26]$.

In fig. $8 \delta \Delta$ is depicted as a function of $C O$ exposure to a surface on which oxygen had been deposited up to $\delta \Delta \approx 0.6^{\circ}$. The rate of change in $\delta \Delta$ increases with increasing crystal temperature and with decreasing oxygen coverage. From 


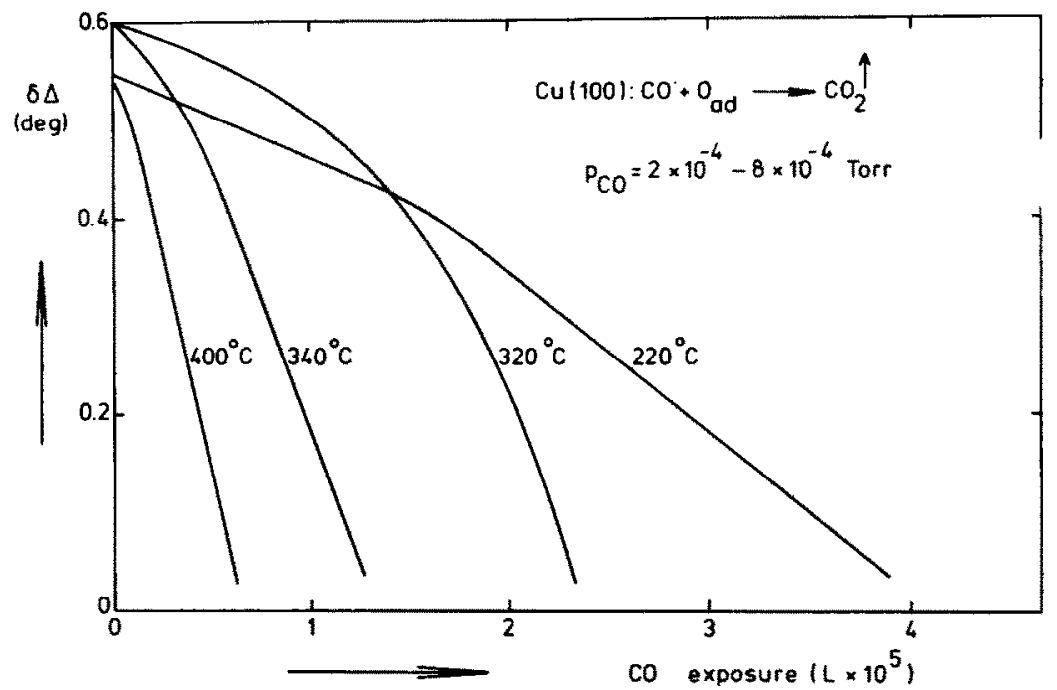

Fig. 8. $\delta \Delta$ versus exposure of $\mathrm{CO}$ to a $\mathrm{Cu}(100)$ surface with preadsorbed oxygen at different temperatures. Off-null irradiance measurements.

experiments with different initial $\delta \Delta\left(\delta \Delta \leqslant 0.6^{\circ}\right)$, it appeared that $\mathrm{d}(\delta \Delta) / \mathrm{d}(p t)$ was only a function of $\delta \Delta$ and $T$, but not of the initial $\delta \Delta$ or the CO pressure $p$. The curves for surface oxygen originating from $\mathrm{O}_{2}$ and from $\mathrm{N}_{2} \mathrm{O}$ turned out to be identical. LEED patterns showed only an increased background for $\delta \Delta \leqslant 0.4^{\circ}$. After the CO exposures, a small amount of oxygen was still present on the surface, as could be detected with AES.

As in the case of this reaction on $\mathrm{Cu}(110)$ [27], the increase in the rate of change of $\delta \Delta$ with decreasing oxygen coverage is explained by the occurrence of the Langmuir-Hinshelwood mechanism; thus for the reaction to take place the $\mathrm{CO}$ molecule must be adsorbed on a free copper site. In our experimental conditions only a very small amount of $\mathrm{CO}$ is adsorbed on $\mathrm{Cu}(100)[24,34,35]$, this amount being proportional to the $\mathrm{CO}$ pressure. Because the chemisorption stage appears to overlap with the incorporation stage around $\delta \Delta=0.5^{\circ}$, the definition of the coverage at which the $\mathrm{CO}$ reaction started, was very poor. So we did not attempt to fit the curves of fig. 8 to a model.

In fig. 9 (line $\mathrm{A}$ ) the values for the reaction probability $P$ (defined as the number of oxygen atoms removed per incident $\mathrm{CO}$ molecule), calculated in the nearly linear midway part of the curves of fig. 8 , are depicted in an Arrhenius plot. At $250^{\circ} \mathrm{C}, P$ is $8 \times 10^{-6} ; E_{\text {act }}$ appears to be $6.9 \pm 0.4 \mathrm{kcal} / \mathrm{mol}$. To obtain the activation energy for the reaction $\mathrm{CO}_{\mathrm{ad}}+\mathrm{O}_{\mathrm{ad}} \rightarrow \mathrm{CO}_{2} \uparrow$ the heat of adsorption of $\mathrm{CO}$ on $\mathrm{Cu}(100)$ must be added. An exact value is not known, but in ref. [24] it is reported that it is intermediate between the value for $\mathrm{Cu}(111)(10-12 \mathrm{kcal} / \mathrm{mol}[36,37])$ and that for 


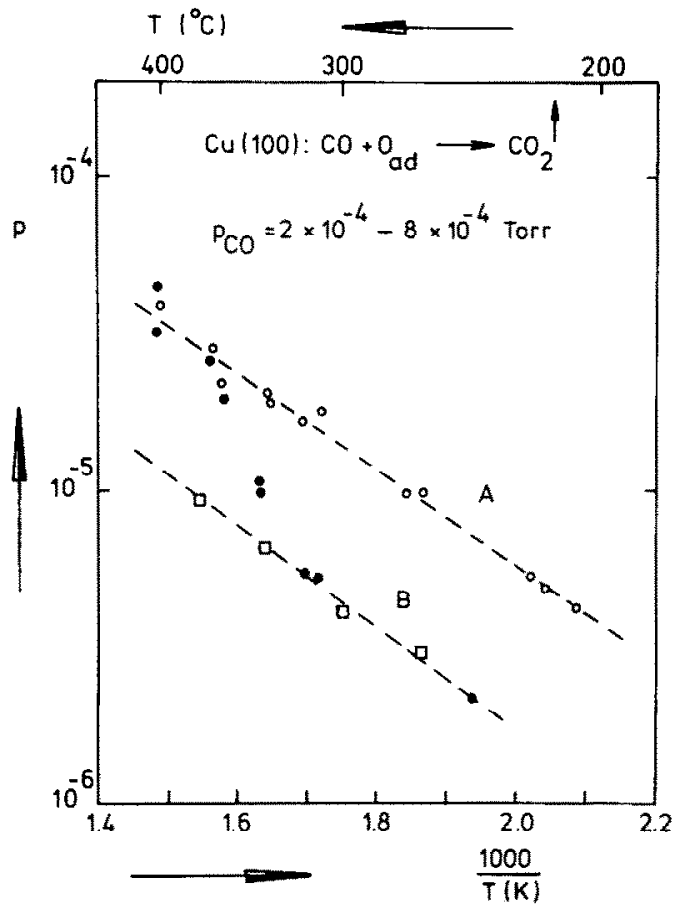

Fig. 9. Arrhenius plots of reaction probabilities $P$ for the reaction of $\mathrm{CO}$ with adsorbed oxygen: (o) initial oxygen coverage $\delta \Delta<0.6^{\circ}$ (line A), ( $\bullet$ ) initial oxygen coverage $\delta \Delta=0.8^{\circ}$, (D) initial oxygen coverage $\delta \Delta=1.2^{\circ}$ (line $\left.\mathrm{B}\right)$.

$\mathrm{Cu}(110)(13.1 \mathrm{kcal} / \mathrm{mol}[38])$. Thus the activation energy for the reaction $\mathrm{CO}_{\mathrm{ad}}+$ $\mathrm{O}_{\mathrm{ad}} \rightarrow \mathrm{CO}_{2}$ is found to be $19-20 \mathrm{kcal} / \mathrm{mol}$.

\subsection{Initial oxygen coverage $>0.5$ monolayer}

Fig. 10 shows $\delta \Delta, \delta \psi, \delta \phi$ and the oxygen Auger signal as a function of $\mathrm{CO}$ exposure at $330^{\circ} \mathrm{C}$ to a surface with preadsorbed oxygen up to $\delta \Delta=0.8^{\circ}$. Initially $\delta \Delta$ and $h_{\mathrm{O}} / h_{\mathrm{Cu}}$ decrease slowly, but at $\delta \Delta \approx 0.5-0.6^{\circ}$ the rates of change increase. The other ellipsometric parameter $\delta \psi$ remains constant till $\delta \Delta \approx 0.4^{\circ}$ and thereafter decreases. The work function change reaches a maximum of about $160 \mathrm{meV}$ at $\delta \Delta \approx 0.6^{\circ}$.

In fig. 11, $\delta \Delta$ versus exposure curves are depicted for different temperatures; the initial $\delta \Delta$ was $0.8^{\circ}$. At the higher temperatures the reaction rate at $\delta \Delta \approx$ $0.55-0.65^{\circ}$ is practically zero. At lower temperatures and also after an oxidation-reduction cycle without sputtering and annealing, no such discontinuity was observed. Finally in fig. 12, $\delta \Delta$ is given as a function of $\mathrm{CO}$ exposure to surfaces with preadsorbed oxygen up to $\delta \Delta=1.2^{\circ}$. Here $\delta \Delta$ decreases faster down to $\delta \Delta \approx$ 


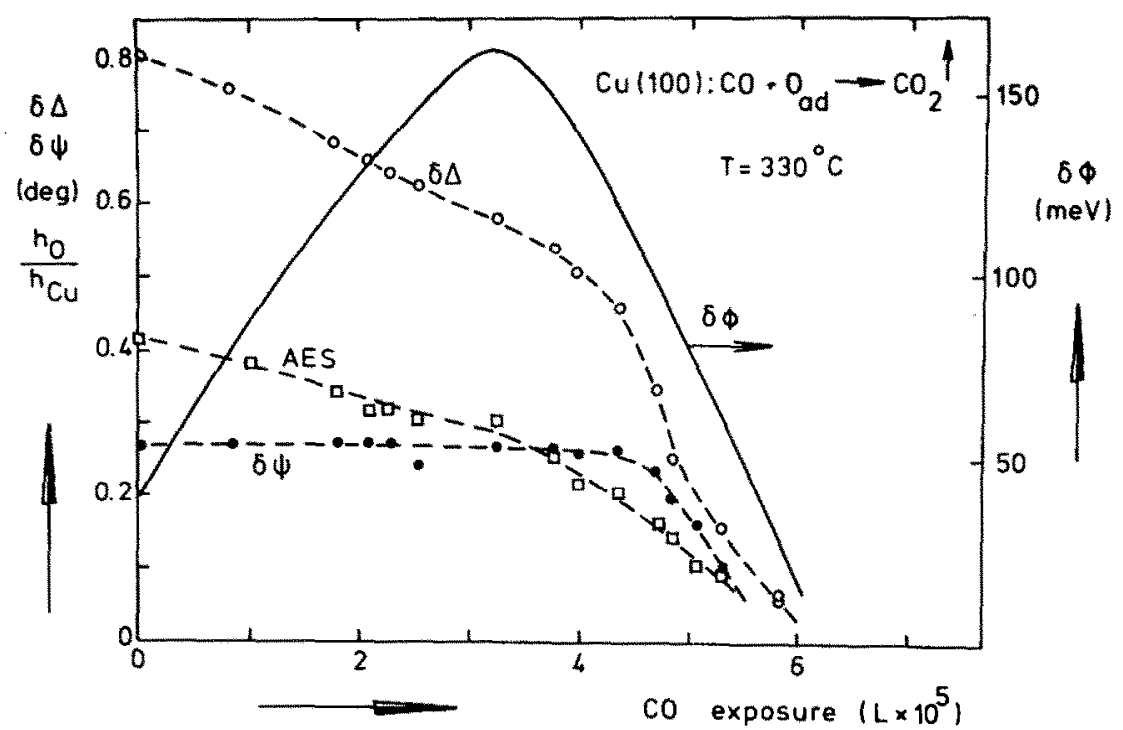

Fig. 10. Oxygen Auger signal (AES), $\delta \Delta, \delta \psi$ and $\delta \phi$ versus exposure of $\mathrm{CO}$ at $330^{\circ} \mathrm{C}$ to a surface with oxygen preadsorbed up to $\delta \Delta=0.8^{\circ}$ ( $\delta \Delta$ and $\delta \psi$ obtained by two-zone measurements).

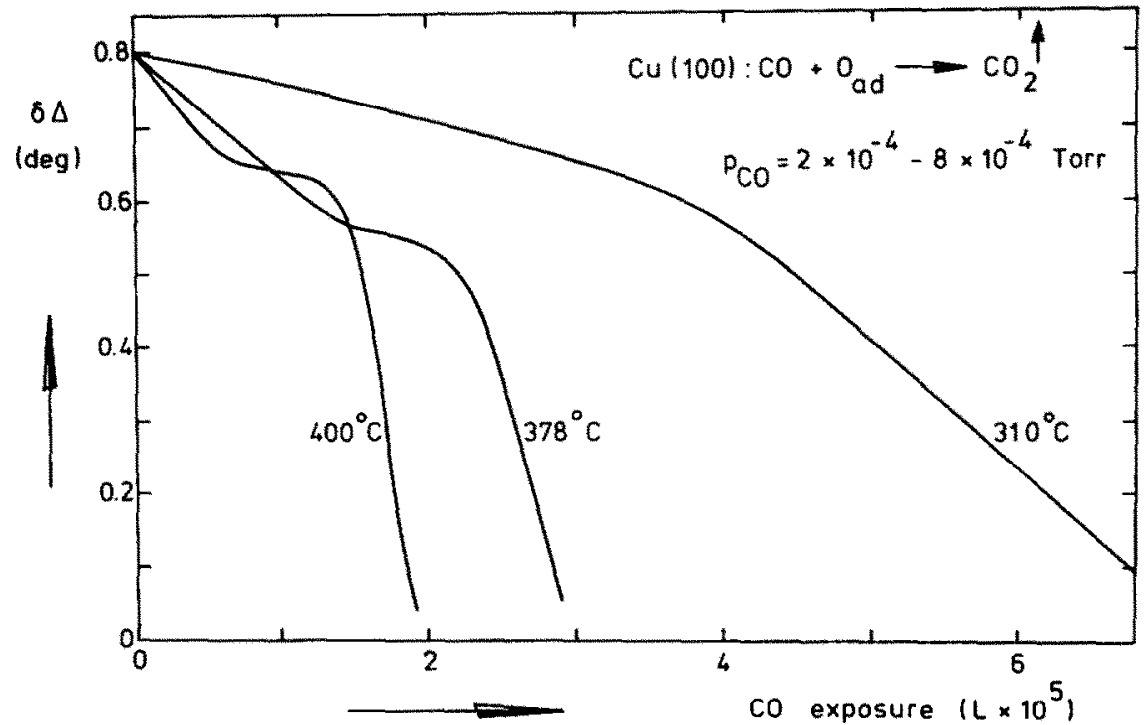

Fig. 11. $\delta \Delta$ versus exposure of $\mathrm{CO}$ to a surface with preadsorbed oxygen up to $\delta \Delta=0.8^{\circ}$ (offnull irradiance measurements). 


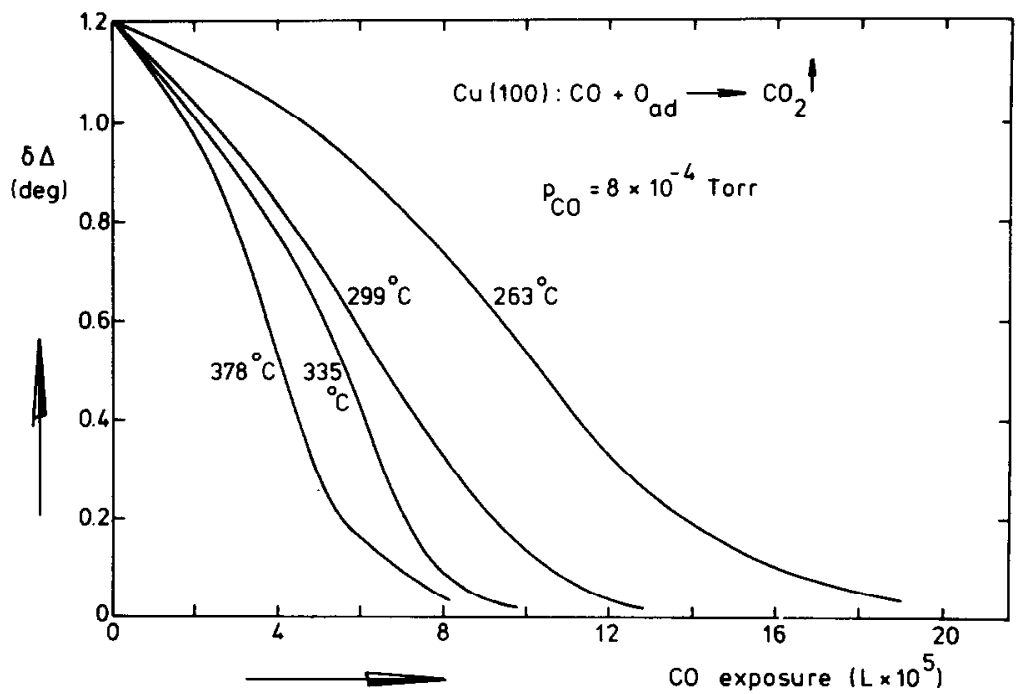

Fig. 12. $6 \Delta$ versus exposure of CO to a surface with preadsorbed oxygen up to $\delta \Delta=1.2^{\circ}$ (offnull irradiance measurements).

$0.6-0.7^{\circ}$, whereafter the rate of change of $\delta \Delta$ becomes constant down to $\delta \Delta \approx$ $0.3^{\circ}$. In such measurements the $\delta \phi$ maximum was lower than $50 \mathrm{meV}$.

After the $\mathrm{CO}$ exposures a small amount of oxygen was still present on the surface, as monitored with AES.

In fig. 9 we have plotted apparent values for $P$ calculated from figs. 11 and 12 at $\delta \Delta \approx 0.35^{\circ}$, using the calibration of eq. (1).

If the initial coverage corresponds to $0.6^{\circ} \leqslant \delta \Delta \leqslant 0.8^{\circ}$, the probabilities, calculated as indicated above, coincide with line $\mathrm{A}$ for $T \geqslant 360^{\circ} \mathrm{C}$, but for lower temperatures they appear smaller. This temperature dependence can be understood from the shapes of the curves of fig. 11: at the higher temperatures (378 and $400^{\circ} \mathrm{C}$ ) at first as a net effect the incorporated oxygen is removed completely, and thereafter chemisorbed oxygen reacts. The near-zero reaction rate is in this view caused by the blocking of the $\mathrm{CO}$ adsorption sites by oxygen adatoms. This does not seem to be the case at the lower temperatures, where the stage with a nearzero reaction rate has disappeared.

The apparent reaction probabilities may be smaller for several reasons. Firstly, different processes may be involved at the same time, which implies that the mean ellipsometric sensitivity is lower than that given by eq. (1). Another reason may be the mechanism, proposed in ref. [28] to explain the reduced reaction probabilities for the same reaction on $\mathrm{Cu}(110)$ at higher initial oxygen coverages. According to this mechanism the growth of islands of bare copper surface is inhibited by small domains, which still contain incorporated oxygen. 
At temperatures $350-450^{\circ} \mathrm{C}$, Ertl [25] has obtained a large value ( $\left.30 \mathrm{kcal} / \mathrm{mol}\right)$ for the activation energy of the reaction of $\mathrm{CO}$ with oxygen, adsorbed in the $(\sqrt{ } 2 \times$ $2 \sqrt{ } 2) \mathrm{R} 45^{\circ}$ structure. His measurements correspond approximately to our measurements of fig. 11, which indeed exhibit a large apparent activation energy in the considered temperature range (cf. fig. 9).

The points on line B (fig. 9) represent the apparent reaction probabilities taken at $\delta \Delta=0.35^{\circ}$ from the curves with initial $\delta \Delta=1.2^{\circ}$ (fig. 11). The slope of line B gives $7 \mathrm{kcal} / \mathrm{mol}$ for the apparent activation energy. This indicates that for lines $A$ and $B$ the same reaction is rate limiting, namely the reaction of adsorbed $C O$ with oxygen on the surface. The considerations given above may apply also for line B; thus line B does not represent precise absolute values for the reaction probabilities. For the type of investigations described here it would be very useful to know the amount of $\mathrm{CO}_{2}$ produced in the several stages of the reaction.

Finally, it should be mentioned that at the higher oxygen coverages $(>0.5)$ there must be empty sites on the surface where the $\mathrm{CO}$ molecules are able to adsorb and react with an oxygen atom in their vicinity, because in all these cases a non-zero reaction rate has been observed, even at completed superstructures (e.g. the $(\sqrt{ } 2 \times$ $2 \sqrt{ } 2) \mathrm{R} 45^{\circ}$ pattern at $\delta \Delta=0.8^{\circ}$ ).

\section{Summary and comparison with $\mathrm{Cu}(111)$ and $\mathrm{Cu}(110)$}

A detailed evaluation of data obtained on the three planes is given in ref. [39].

\subsection{Kinetics in the chemisorption stage}

On $\mathrm{Cu}(100)$ and (111) independent of the temperature the same linear relationships were observed between the change in the ellipsometric parameter $\Delta, \delta \Delta$, and the amount of adsorbed oxygen. At room temperature this relationship was also found for $\mathrm{Cu}(110)$. However, there $\delta \Delta$ and the change in the other ellipsometric parameter, $\delta \psi$, appeared to be functions of the azimuth of the plane of incidence of the light beam and of the temperature. A calibration of $\delta \Delta$ and the oxygen Auger signal was obtained via LEED patterns.

On the three planes upon chemisorption of $\mathrm{O}_{\mathrm{ad}}$ during the reaction with $\mathrm{O}_{2}$ and the decomposition of $\mathrm{N}_{2} \mathrm{O}\left(\mathrm{N}_{2} \mathrm{O} \rightarrow \mathrm{N}_{2} \uparrow+\mathrm{O}_{\mathrm{ad}}\right)$ a saturation coverage $\theta$ of about 0.5 (oxygen atoms per copper surface atom) was obtained, strongly suggesting dissociative adsorption of $\mathrm{O}_{2}$. At this coverage $\mathrm{Cu}(110)-(2 \times 1)-\mathrm{O}$ and $\mathrm{Cu}(100)$ $(\sqrt{ } 2 \times \sqrt{ } 2) \mathrm{R} 45^{\circ}-\mathrm{O}$ patterns were observed, whereas on $\mathrm{Cu}(111)$ the adsorption takes place randomly.

At room temperature the initial sticking coefficient $s(0)$ for $\mathrm{O}_{2}$ increases in the order $\operatorname{Cu}(111)\left(s(0)=10^{-3}\right), \operatorname{Cu}(100)\left(10^{-2}\right)$ and $\operatorname{Cu}(110)(0.2)$. For $(111)$ and (100) the apparent activation energy depends on the sample temperature and is about $1.5 \mathrm{kcal} / \mathrm{mol}$ for $25<T<200^{\circ} \mathrm{C}$ and $3.8 \mathrm{kcal} / \mathrm{mol}$ for $200<T<400^{\circ} \mathrm{C}$. On 
$\mathrm{Cu}(110) s(0)$ appeared independent of the temperature. On $\mathrm{Cu}(111) s(\theta)$ remains constant up to $\theta \approx 0.3$, whereas on the other two planes $s(\theta)$ drops rapidly with increasing $\theta$. For the explanation of the experimental data for $\mathrm{O}_{2}$ precursor kinetics is favoured over Langmuir kinetics.

The rate of decomposition of $\mathrm{N}_{2} \mathrm{O}$ depends strongly on the crystallographic orientation of the surface. The initial reaction probability $s(0)$ at room temperature decreases in the order $\mathrm{Cu}(110)(s(0) \approx 0.15),(100)\left(5 \times 10^{-5}\right)$ and $(111)$ (extrapolated value $\sim 10^{-9}$ ). The measured activation energy $E_{\text {act }}$ increases in the order (110) $(-2 \mathrm{kcal} / \mathrm{mol}),(100)(3.2 \mathrm{kcal} / \mathrm{mol})$ and $(111)(10.4 \mathrm{kcal} / \mathrm{mol})$. The decrease of $s$ as a function of $\theta$ is slower on $\mathrm{Cu}(111)$ than on (110) and (100). On the latter two planes $E_{\text {act }}$ increases with increasing coverage. A larger $E_{\text {act }}$ appears to be accompanied by a larger pre-exponential factor (compensation effect).

The oxidation of $\mathrm{CO}$ by preadsorbed oxygen appears to be a non plane-specific reaction. The probability for an incident $\mathrm{CO}$ molecule to react is about $10^{-5}$ at temperatures ranging from 200 to $400^{\circ} \mathrm{C}$. It is proposed that the reaction proceeds between two chemisorbed reactants (Langmuir-Hinshelwood mechanism). The observed small differences in measured activation energies are compensated by differ. ences in heats of adsorption of $\mathrm{CO}$ on the various planes. For the reaction of adsorbed $\mathrm{CO}$ with adsorbed oxygen an activation energy of 19 to $20 \mathrm{kcal} / \mathrm{mol}$ is obtained. No differences have been found for surface oxygen originating from $\mathrm{O}_{2}$ or $\mathrm{N}_{2} \mathrm{O}$.

\subsection{Stages of initial oxidation}

For $\mathrm{Cu}(110)$ and $\mathrm{Cu}(100)$ three stages in the initial interaction with $\mathrm{O}_{2}$ are discerned. The first (chemisorption) stage is accompanied by an increase in work function. After a maximum has been reached (370 meV for $\mathrm{Cu}(110)$ and $330 \mathrm{meV}$ for $\mathrm{Cu}(100)$ ), the work function decreased upon further oxygen exposure. The decrease amounted to $80 \mathrm{meV}$ on $\mathrm{Cu}(110)$ and $330 \mathrm{meV}$ on $\mathrm{Cu}(100)$ and is interpreted to be caused by incorporation of oxygen beneath the surface but in the immediate surface region (second stage). In this stage $\psi$ remained constant, whereas $\delta \Delta$ and the oxygen Auger signal increased, although less strongly than in the first stage. At $200^{\circ} \mathrm{C}$ the sticking coefficient at the start of the second stage is about $10^{-4}$ on $\mathrm{Cu}(110)$ and $10^{-3}$ on $\mathrm{Cu}(100)$; the apparent activation energies are $4.5 \mathrm{kcal} / \mathrm{mol}$ for $\mathrm{Cu}(110)$ and $3.2 \mathrm{kcal} / \mathrm{mol}$ for $\mathrm{Cu}(100)$. At the end of the second stage, where $\delta \phi$ and the oxygen Auger signal become constant, on $\mathrm{Cu}(110)$ a $\mathrm{c}(6 \times$ 2) and on $\mathrm{Cu}(100)$ a $(\sqrt{ } 2 \times 2 \sqrt{ } 2) \mathrm{R} 45^{\circ}$ LEED pattern was observed. The coverage is proposed to correspond to about one monolayer on (110) and $\frac{3}{4}$ on (100).

In the third stage only $\delta \Delta$ changed upon further oxygen uptake, on $\mathrm{Cu}(110)$ immediately after the second stage, and on $\mathrm{Cu}(100)$ after an incubation exposure. For both planes the rate of change of $\delta \Delta$ is equal: $s$ amounts to $10^{-5}$ at $200^{\circ} \mathrm{C}$ and $E_{\text {act }}$ to $4.5 \mathrm{kcal} / \mathrm{mol}$.

The surfaces, oxidized up to the third stage, can nearly totally be reduced with 
$\mathrm{CO}$. At equal coverages the reaction probability is smaller for larger initial oxygen coverages.

\section{Acknowledgement}

The authors thank Dr. O.L.J. Gijzeman for helpful discussions and Mr. A.H.J. Huijbers for technical assistance. The investigations were supported by the Netherlands Foundation of Chemical Research (SON) with financial aid from the Netherlands Organization for the Advancement of Pure Research (ZWO).

\section{References}

[1] R.N. Lee and H.E. Farnsworth, Surface Sci. 3 (1965) 461.

[2] G. Ertl, Surface Sci. 6 (1967) 208.

[3] G.W. Simmons, D.F. Mitchell and K.R. Lawless, Surface Sci. 8 (1967) 130.

[4] A. Oustry, L. Lafourcade and A. Escaut, Surface Sci. 40 (1973) 545.

[5] L. McDonnell and D.P. Woodruff, Surface Sci. 46 (1974) 505.

[6] M.J. Braithwaite, R.W. Joyner and M.W. Roberts, J.C.S. Faraday Disc. 60 (1975) 89.

[7] P. Hofmann, R. Unwin, W. Wyrobisch and A.M. Bradshaw, Surface Sci. 72 (1978) 635.

[8] C. Benndorf, B. Egert, G. Keller, H. Seidel and F. Thieme, J. Phys. Chem. Solids 40 (1979) 877.

[9] L. McDonnell, D.P. Woodruff and K.A.R. Mitchell, Surface Sci. 45 (1974) 1.

[10] C.B. Duke, N.O. Lipari and G.E. Laramore, Nuovo Cimento 23B (1974) 241.

[11] J.R. Noonan, D.M. Zehner and L.H. Jenkins, Surface Sci. 69 (1977) 731.

[12] S. Kono, C.S. Fadley, N.F.T. Hall and Z. Hussain, Phys. Rev. Letters 41 (1978) 117.

[13] S. Kono, S.M. Goldberg, N.F.T. Hall and C.S. Fadley, Phys. Rev. Letters 41 (1978) 1831.

[14] S.P. Holland, B.J. Garrison and M. Winograd, Phys. Rev. Letters 43 (1979) 220.

[15] D.R. Lloyd, C.M. Quinn and N.V. Richardson, Surface Sci. 68 (1977) 419.

[16] J.E. Boggio, J. Chem. Phys. 53 (1970) 3544.

[17] T.A. Delchar, Surface Sci. 27 (1971) 11.

[18] J.H. Onuferko and D.P. Woodruff, Surface Sci. 95 (1980) 555.

[19] P. Hofmann, Thesis, Techn. Univ. of Munich (1979).

[20] D.T. Ling, J.N. Miller, P.A. Pianetta, D.L. Weissman, I. Lindau and W.E. Spicer, J. Vacuum Sci. Technol. 15 (1978) 495.

[21] C. Benndorf, B. Egert, G. Keller and F. Thieme, Surface Sci. 74 (1978) 216.

[22] F.W. Young, J.V. Cathcart and A.T. Gwathmey, Acta Met. 4 (1956) 145.

[23] J.J.F. Scholten and J.A. Konvalinka, Trans. Faraday Soc. 65 (1969) 2465.

[24] J. Pritchard, J. Vacuum Sci. Technol. 9 (1972) 895.

[25] G. Ertl, Surface Sci. 7 (1967) 309.

[26] F.H.P.M. Habraken, E.Ph. Kieffer and G.A. Bootsma, Surface Sci. 83 (1979) 45.

[27] F.H.P.M. Habraken and G.A. Bootsma, Surface Sci. 87 (1979) 333.

[28] F.H.P.M. Habraken, G.A. Bootsma, P. Hofmann, S. Hachicha and A.M. Bradshaw, Surface Sci. 88 (1979) 285.

[29] K. Besocke and S. Berge, Rev. Sci. Instr. 47 (1976) 840.

[30] F.H.P.M. Habraken, O.L.J. Gijzeman and G.A. Bootsma, Surface Sci. 96 (1980) 482.

[31] D.A. King and M.G. Wells, Proc. Roy. Soc. (London) A339 (1974) 245.

[32] M. Jardinier-Offergeld and F. Bouillon, J. Vacuum Sci. Technol. 9 (1972) 770. 
[33] F.H.P.M. Habraken and G.A. Bootsma, to be published.

[34] S.A. Isa, R.W. Joyner and M.W. Roberts, J.C.S. Trans. Faraday Soc. I, 74 (1978) 546.

[35] J. Küppers, F. Nitschké, K. Wandelt, G. Ertl and C.R. Brundle, J.C.S. Trans. Faraday Soc. I, 75 (1979) 984.

[36] H. Conrad, G. Ertl, J. Küppers and E.E. Latta, Solid State Commun. 17 (1975) 613.

[37] J. Kessler and F. Thieme, Surface Sci. 67 (1977) 405.

[38] K. Horn, M. Hussain and J. Pritchard, Surface Sci. 63 (1977) 244.

[39] F.H.P.M. Habraken, Thesis, Univ. of Utrecht (1980). 